\title{
PENGARUH EDUKASI TERHADAP PENGETAHUAN DAN SIKAP IBU HAMIL TENTANG INISIASI MENYUSUI DINI (IMD) DI WILAYAH KERJA PUSKERMAS PARANGLOE KABUPATEN GOWA
}

\section{THE EFFECT OF EDUCATION ON PREGNANCY KNOWLEDGE AND ATTITUDE ABOUT BREASTFEEDING INITIATION IN PUSKESMAS WORKING REGION PARANGLOE DISTRICT GOWA}

\author{
Sukmawati ${ }^{1}$, Stang ${ }^{2}$, Nadjib Bustan ${ }^{3}$ \\ ${ }^{1}$ Bagian Kesehatan Reproduksi, Fakultas Kesehatan Masyarakat, Universitas Hasanuddin \\ ${ }^{2}$ Bagian Biostatistik/KKB,Fakultas Kesehatan Masyarakat, Universitas Hasanuddin \\ ${ }^{3}$ Bagian Biostatistik,Fakultas Matematika dan Ilmu Pengetahuan Alam, Universitas Negeri \\ Makassar \\ Email: sukmaarif87@gmail.com
}

\begin{abstract}
ABSTRAK
Inisiasi Menyusu Dini (IMD) adalah bayi diberi kesempatan memulai menyusu sendiri segera setelah lahir/dini, dengan membiarkan kontak kulit bayi dengan kulit ibu setidaknya satu jam atau lebih, sampai menyusu pertama selesai. Praktek IMD di Indonesia kurangdari 1 jam setelah bayi lahir hanya $34.5 \%$. Kurangnya pengetahuan dari orang tua sehingga IMD masih jarang dipraktekkan. Penelitian ini bertujuan untuk mengetahui pengaruh edukasi IMD terhadap pengetahuan dan sikap ibu hamil tentang IMD di wilayah kerja Puskesmas Palangloe Kabupaten Gowa. Jenis penelitian dengan metode quasi eksperiment dengan rancanganthe randomized pretest-posttest contol group design. Populasi dalam penelitian ini adalah seluruh ibu hamil yang berada di wilayah kerja puskesmas sebanyak 60 ibu hamil pada bulan Januari-April 20017. Penarikan sampel menggunakan metode total sampling 60 ibu hamil. Pengumpulan data dilakukan dengan menggunakan kuesioner. Uji statistik yang digunakan Mann Whitney, Wilcoxon dan Paired t Test. Hasil penelitian menunjukkan ada perbedaan kelompok intervensi dengan kelompok kontrol sebelum dan sesudah intervensi IMD dengan $\mathrm{p}<0,05$ dan ada pengaruh edukasi terhadap pengetahuan dan sikap ibu tentang IMD dengan $\mathrm{p}<0,05$ (pengetahuan kelompok intervensi $\mathrm{p}=0,000$, pengetahuan kelompok kontrol $\mathrm{p}=0,000$; sikap kelompok intervensi $\mathrm{p}=0,000$ dan sikap kelompok kontrol $\mathrm{p}=0,000$ ). Terdapat peningkatan pengetahuan dan sikap ibu hamil mengenai IMD setelahdilakukan edukasi (penyuluhan).
\end{abstract}

Kata Kunci :IMD, sikap, pengetahuan

\begin{abstract}
Early Breastfeeding Initiation (EBI) isthe baby given the opportunity to start their ownnursing immediately after birth / early, by letting the baby skin contact with the skin's motherat least one hour or more, until the first feeding is completed. However, lack of knowledge ofparents so that the IMD is still rarely practiced. This study aims to determine the effect of educational EBI on knowledge and attitude of pregnant women about EBI in the work area of Puskesmas Palangloe Gowa District. Type of research with quasi experiment method with the randomized pretest-posttestcontol group design. The population in this study were all pregnant women in the work area of puskesmas as much as 60 pregnant women in January-April 20017. Sampling using total sampling method 60 pregnant women. The data were collected by using questionnaires. Statistic test used by Mann Whitney, Wilcoxon and Paired $t$ Test. The results showed that there was a difference of the intervention group with the control group before and after the EBI intervention with $p<0.05$ and there was an effect of education on knowledge and attitude about EBI with $p<0,05$ (knowledge of intervention group $p=0,000,=0,000$, intervention group attitude $p=0,000$ and attitude of control group $p=0,000$ ). There were improved of knowledge level and attitude towards EBI on pregnant woman before and after counseling
\end{abstract} Keywords:EBI, attitude, knowledge 


\section{PENDAHULUAN}

Inisiasi Menyusu Dini (IMD) merupakan program yang sedang gencar dianjurkan pemerintah. Data terbaru hasil Riskesdas 2013, persentase nasional proses mulai menyusu kurang dari satu jam (IMD) setelah bayi lahir adalah 34,5 persen, dengan persentase tertinggi di Nusa Tenggara Barat $(52,9 \%)$ danterendah di Papua Barat (21,7\%). Sebagian besar proses menyusui dilakukan pada kisaran waktu 1 6 jam setelah bayi lahir tapi masih ada 13,7 $\%$ proses mulai disusui dilakukan setelah 48 jam. Sedangkan propinsi Sulawesi Selatan menunjukkan inisiasi menyusu dini $<1$ jam adalah 44,9

$\%$ dan pada kisaran 1-6 jam yaitu $26 \%$.

IMD dapat mengurangi $22 \%$ kematian bayi 28 hari, berarti IMD mengurangi kematian balita 8,8 \%. Jika bayi diberi kesempatan menyusu dalam waktu satu jam pertama dengan membiarkan kontak kulit ke kulit, maka $22 \%$ nyawa bayi dibawah 28 hari dapat diselamatkan jika mulai menyusu pertama saat bayi berusia diatas 2 jam dan dibawah 24 jam pertama, tinggal $16 \%$ nyawa bayi dibawah 28 hari dapat diselamatkan. Inisiasi menyusu dini merupakan salah satu cara untuk mencegah perdarahan postpartum primer karena mempengaruhi involusi uterus karena saat menyusui terjadi rangsangan dan dikeluarkannya hormon antara lain oksitosin yang berfungsi selain merangsang kontraksi otot-otot polos payudara, juga menyebabkan terjadinya kontraksi dan retraksi otot uterus (Nurhikmah, 2014).

Pemerintah propinsi Sulawesi Selatan menjadi propinsi pertama di Indonesia yang mengesahkan Perda nomor

6 tahun 2010. Hak seorang ibu untuk mendapatkan informasi tentang IMD serta kesempatan ibu bersalin dan bayi untuk melakukan insiasi menyusu dini dijelaskan dalam pasal 10 ayat 1,2 dan 3 yang menyatakan institusi pelayanan kesehatan dan penolong persalinan wajib menyediakan komunikasi, informasi dan edukasi (KIE) tentang manfaat IMD dan wajib memberikan kesempatan dan membantu ibu dan bayi melakukan IMD.Untuk mencapai hal tersebut, diperlukan edukasi berupa pemberian informasi yang objektif dan lengkap, dilakukan secara sistematik dengan panduan keterampilan komunikasi interpersonal, penguasaan klinik sehingga ibu mampu menyerap informasi tersebut dan mampu mengaplikasikan dalam kehidupan sehari - hari. Edukasi sangat berpengaruh terhadap perubahan pengetahuan dan sikap (Bohari dkk, 2011).

Berdasarkan studi pendahuluan terhadap beberapa ibu hamil di puskesmas Parangloe, banyak ibu yang merasa kasihan dan tidak percaya seorang bayi yang baru lahir dapat mencari sendiri puting ibunya. Ataupun rasa malu untuk meminta dokter/bidan yang membantu persalinan untuk melakukannya. Maka dari itu dilakukan penelitian untuk menganalisis pengaruh edukasi terhadap pengetahuan dan sikap ibu hamil tentang IMD di wilayah kerja Puskesmas Parangloe kabupaten Gowa. Edukasi ini dilakukan melalui penyuluhan dengan menggunakan media video dan leaflet IMD. Hasil dari penelitian ini diharapkan dapat meningkatkan perilaku ibu hamil dalam pelaksanaan IMD.

\section{BAHAN DAN METODE LokasiPenelitian}

Lokasi penelitian di wilayah kerja Puskesmas Parangloe Gowa yang dipilih secara otal. Berdasarkan data dari Puskesmas Parangloe 2016, persentase bayi yang mendapat IMD di Puskesmas sebesar $8,01 \%$ yang tergolong masih rendah cakupannya. Jenis penelitian yang digunakan yaitu rancangan quasi eksperimental dengan rancangan the randomized pretest-post test contol group design. Penelitian ini melibatkan dua kelompok subjek yang diuji pretest dan post test. Satu kelompok (perlakuan) diberi penyuluhan IMD dan satu kelompok

Lainnya (kontrol) tidak mendapatkan penyuluhan. Adapun variable 
dalam Penelitian ini yaitu pengetahuan dan sikap.

\section{PopulasidanSampel}

Populasi dalam penelitian ini adala hseluruh ibu hamil yang berada di kecamatan Parangloe Gowa. Sampel penelitian sebanyak 60 ibuhamiltersebar di 7 desa yang tercatatdalambuku register kohort ibu hamil pada bulan Januari - April 2017

\section{Pengumpulan Data}

Jenis data dalam penelitian ini adalah data sekunder dari Puskesmasdan data primer dari data isian oleh responden kuesioner. Sampel dibagi dua kelompok masing - masingterdiridari 30 orang untuk kelompok intervensi (ibu hamil yang mendapatkan penyuluhan) dan 30 orang untuk kelompok kontrol (ibu hamil yang tidak mendapatkan penyuluhan). Ibu hamil akan dikumpulkan oleh coordinator bidan bekerjasama dengan bidan desa serta tenaga promosi kesehatan kemudian dibagikan leaflet dan diputarkan video sambil peneliti memberikan penyuluhan.

\section{Analisis data}

Analisis data yang dilakukan adalah analisis univariat, dan biavariat melalui tabulasi silang dengan menggunakan SPSS for windows 21.0.

\section{HASIL PENELITIAN}

Tabel 1 memperlihatkan hasil analisis univariat, responden paling banyak pada kelompok umur 21-25 tahun sebesar 33,3\% sedangkan responden paling sedikit pada kelompok umur $\leq 20$ tahun kelompok kontrol sebesar 3,3\%. Pendidikan terakhir responden kontrol paling banyak yaitu SD $40 \%$ dibandingkan akademi yaitu sebesar $3,4 \%$ kelompok control. Pekerjaan responden paling banyak sebagai ibu rumah tangga sebesar $90 \%$ pada kelompok perlakuan sedangkan jenis pekerjaan paling sedikit pada kelompok kontrol yaitu pegawai honorer sebesar 3,4\%. Distribusi responden berdasarkan penghasilan keluarga yang terbanyak senilai Rp.1.000.0002.000.000,- sebesar $60 \%$ pada kelompok kontrol sedangkan penghasilan keluarga paling sedikit senilai.

$>$ Rp2.000.000,- pada kelompok perlakuan sebesar 6,7\%. Distribusi responden berdasarkan umur kehamilan yang terbanyakpada trimester III sebesar 56,7\% pada kelompok perlakuan sedangkan paling sedikit 3,3\% pada trimester III kelompok control. Responden berdasarkan keterpaparan informasi IMD yang terbanyak yaitu yang tidak pernah mendapatkan informasi IMD sebesar 70\% pada kelompok kontrol. Distribusi responden menurut tindakan IMD yang terbanyak pada kelompok perlakuan yaitu semuanya melakukan IMD sedangkan pada kelompok kontrol tidak IMD sebesar 100\%.

Tabel 2 menunjukkan bahwa untuk pengetahuan pre test pada kelompok perlakuan, pengetahuan cukup

persentasenya lebih besar (83,3\%), pengetahuan post test pada kelompok perlakuan (60\%), sikap ibu hamil pada tahap pre test, kelompok sikap kategori cukup (100\%), dan sikap ibu hamil setelah intervensi, pada kelompok perlakuan kategori baik (86,7\%).Pada Tabel 3 hasil analisa menunjukkan bahwa nilai rata-rata pada kelompok perlakuan 5,40 dan kelompok kontrol 7,23 , pengetahuan setelah intervensi yang dilakukan bahwa nilai rata-rata pada kelompok perlakuan 7,83 dan kelompok kontrol 7,73, sikap sebelum intervensi nilai rata-rata pada kelompok perlakuan 6,76 dan kelompok kontrol 6,03, sikap sebelum intervensi nilai rata-rata pada kelompok perlakuan 8,53 dan kelompok kontrol 8,10. Hasil analisa statistik menunjukkan ada perbedaan pengetahuan tentang IMD antara kelompok perlakuan dan kelompok kontrol sebelum dan sesudah intervensi. Ada perbedaan sikap tentang IMD antara kelompok perlakuan dan kelompok kontrol sebelum dan sesudah intervensi. 
Tabel 1.Distribusi KarakteristikResponden

\begin{tabular}{|c|c|c|c|c|}
\hline \multirow{3}{*}{ Karakteristik Umum } & \multicolumn{4}{|c|}{ Jenis Responden } \\
\hline & \multicolumn{2}{|c|}{ Perlakuan } & \multicolumn{2}{|c|}{ Kontrol } \\
\hline & $\mathrm{n}$ & $\%$ & $\mathrm{n}$ & $\%$ \\
\hline \multicolumn{5}{|l|}{ Umur (Tahun) } \\
\hline$\leq 20$ & 4 & 13,3 & 1 & 3,3 \\
\hline $21-25$ & 10 & 33,3 & 10 & 33,3 \\
\hline $26-30$ & 6 & 20,0 & 4 & 13,3 \\
\hline $31-35$ & 5 & 16,7 & 5 & 16,7 \\
\hline $36-40$ & 3 & 10,0 & 5 & 16,7 \\
\hline $41-45$ & 2 & 6,7 & 5 & 16,7 \\
\hline \multicolumn{5}{|l|}{ Tingkat Pendidikan Terakhir } \\
\hline $\mathrm{SD}$ & 11 & 36,6 & 12 & 40,0 \\
\hline SMP & 8 & 26,7 & 10 & 33,3 \\
\hline SMA & 8 & 26,7 & 7 & 23,3 \\
\hline Akademi/PT & 3 & 10,0 & 1 & 3,3 \\
\hline \multicolumn{5}{|l|}{ Pekerjaan } \\
\hline Ibu Rumah Tangga & 27 & 90,0 & 25 & 83,3 \\
\hline Wiraswasta & 0 & 0,0 & 4 & 13,3 \\
\hline Pegawai honorer & 3 & 10,0 & 1 & 3,4 \\
\hline \multicolumn{5}{|l|}{ Penghasilan Keluarga (Rp) } \\
\hline$<1.000 .000,-$ & 11 & 36,7 & 8 & 26,7 \\
\hline $1.000 .000-2.000 .000,-$ & 17 & 56,6 & 18 & 60,0 \\
\hline$>2.000 .000,-$ & 2 & 6,7 & 4 & 13,3 \\
\hline \multicolumn{5}{|l|}{ Trimester (Minggu) } \\
\hline I $(1-12)$ & 2 & 6,6 & 21 & 70,0 \\
\hline II $(13-28)$ & 11 & 36,7 & 8 & 26,7 \\
\hline III ( $29-40)$ & 17 & 56,7 & 1 & 3,3 \\
\hline \multicolumn{5}{|l|}{ Terpapar Informasi IMD } \\
\hline Pernah & 11 & 36,7 & 9 & 30,0 \\
\hline Tidak Pernah & 19 & 63,3 & 21 & 70,0 \\
\hline \multicolumn{5}{|l|}{ Status IMD } \\
\hline IMD & 17 & 100,0 & 0 & 0,0 \\
\hline Tidak IMD & 0 & 0,0 & 1 & 100,0 \\
\hline
\end{tabular}

Sumber Data Primer, 2017. 
Tabel 2.DistribusiRespondenBerdasarkanVariabel Independen Responden

\begin{tabular}{lcccc}
\hline \multirow{2}{*}{ Variabel Independen } & \multicolumn{5}{c}{ Jenis Responden } \\
\cline { 2 - 3 } & \multicolumn{2}{c}{ Perlakuan } & & Kontrol \\
\cline { 2 - 5 } Pengetahuan Pre Test & 2 & 6,7 & 0 & $\%$ \\
Baik & 25 & 83,3 & 26 & 0 \\
Cukup & 3 & 10,0 & 4 & 13,3 \\
Kurang & & & & \\
Pengetahuan Post Test & 18 & 60,0 & 10 & 33,3 \\
Baik & 12 & 40,0 & 19 & 63,4 \\
Cukup & 0 & 0,0 & 1 & 3,3 \\
Kurang & 7 & 23,3 & 0 & 0 \\
Sikap Pre Test & 23 & 76,7 & 30 & 100,0 \\
Baik & 0 & 0,0 & 0 & 0,0 \\
Cukup & & & & \\
Kurang & 26 & 86,7 & 24 & 30,0 \\
Sikap Post Test & 4 & 13,3 & 6 & 66,7 \\
Baik & 0 & 0,0 & 0 & 3,3 \\
Cukup & & & & \\
Kurang & & & & \\
\hline
\end{tabular}

Sumber Data Primer, 2017

Tabel 3. Analisis Perbedaan Pengetahuan dan Sikap Responden

\begin{tabular}{llll}
\hline Analisis Perbandingan & $\mathrm{n}$ & Mean & $\mathrm{P}$ \\
\hline Pengetahuan sebelum intervensi & & & \\
Kelompok perlakuan & 30 & 5.4000 & 0.114 \\
Kelompok kontrol & 30 & 5.2333 & \\
Pengetahuansetelahintervensi & & & \\
Kelompok perlakuan & 30 & 7.8333 & 0.000 \\
Kelompok kontrol & 30 & 7,7333 & \\
Sikapsebelumintervensi & & & \\
Kelompok perlakuan & 30 & 6.7667 & \\
Kelompok kontrol & 30 & 6.0333 & \\
Sikapsetelahintervensi & & & \\
Kelompok perlakuan & 30 & 8.5333 & 0.000 \\
Kelompok kontrol & 30 & 8.1000 & \\
\hline
\end{tabular}

\section{Sumber Data Primer, 2017}

Hasil analisis Tabel 4 dengan uji statistik menunjukkan bahwa perbandingan pengetahuan kelompok intervensi nilai rata-rata 5,40 dan 7,83 dan kelompok kontrol 5,23 dan 7,73. Perbandingan sikap kelompok intervensi diperoleh nilai ratarata 6,76 dan 8,53 dan sikap pada kelompok kontrol adalah 6,03 dan 8,10. Hasil uji statistik diperoleh masing-masing nilai $\mathrm{p}=0,000(\mathrm{p}<0,05)$, dapat disimpulkan bahwa ada perbedaan bermakna antara sebelum dan sesudah intervensi edukasi terhadap pengetahuan responden tentang IMD pada kelompok intervensi maupun kontrol dan ada perbedaan bermakna antara sebelum dan sesudah intervensi edukasi terhadap sikap responden tentang IMD pada kelompok intervensi maupun kontrol. 
Tabel 4. Analisis Pengaruh Edukasi terhadap Pengetahuan dan Sikap IMD Responden

\begin{tabular}{lcccc}
\hline Analisis Intervensi & $\mathrm{n}$ & Mean & SD & P \\
\hline Pengetahuan IMD kelompok intervensi & & & & \\
Sebelum Intervensi & 30 & 5.4000 & 1.52225 & \\
Sesudah Intervensi & & 7.8333 & 0.79148 & 0.000 \\
$\begin{array}{l}\text { PengetahuanIMD kelompok intervensi } \\
\text { Sebelum Intervensi }\end{array}$ & 5.2333 & 1.65432 & \\
Sesudah Intervensi & 30 & 7.7333 & 1.14269 & 0.000 \\
$\begin{array}{l}\text { SikapIMD kelompokintervensi } \\
\text { Sebelum Intervensi }\end{array}$ & & & \\
Sesudah Intervensi & 30 & 8.5333 & 0.86037 & 0.000 \\
$\begin{array}{l}\text { SikapIMD kelompok kontrol setelahintervensi } \\
\text { Sebelum Intervensi }\end{array}$ & & & \\
Sesudah Intervensi & 30 & 8.0333 & 0.96431 & \\
& & & 1.44676 & 0.000 \\
\hline
\end{tabular}

\section{Sumber Data Primer, 2017}

\section{PEMBAHASAN}

Pada penelitian ini terlihat pada masing-masing kelompok terjadi peningkatan. Pada kelompok perlakuan sebelum diberikan edukasi sebanyak 6,7 \% responden memiliki pengetahuan baik dan setelah diberi penyuluhan (edukasi), meningkat menjadi $60 \%$. Sedangkan pada kelompok kontrol, tidak ada yang memiliki pengetahuan baik (0 \%), dan setelah dilakukan penilaian kembali, ibu yang memiliki pengetahuan baik meningkat menjadi $10 \%$. Hal ini disebabkan karena sebagian besar ibu hamil bekerja sebagai ibu rumah tangga maka responden mempunyai waktu lebih banyak untuk memperoleh informasi tentang inisiasi menyusu dini (Wahyuningsih, 2012). Hasil analisis perbedaan pengetahuan setelah edukasi pada kelompok perlakuan dan kontrol menunjukkan $\mathrm{p}=0,000(\mathrm{p}<0,05)$. Ini berarti ada perbedaan pengetahuan tentang IMD antara kelompok perlakuan dan kontrol sesudah edukasi. Penelitian ini sejalan dengan penelitian yang dilakukan oleh Wahyuningsih (2013) dan Rahmawati (2015) yang menyatakan bahwa ada hubungan yang bermakna antara pengetahuan ibu dengan pelaksanaan IMD yang berarti semakin baik pengetahuan ibu maka semakin baik pula tindakan ibu dalam pelaksanaan IMD.

Penyuluhan yang dapat meningkatkan pengetahuan juga berpengaruh terhadap sikap ibu hamil mengenai IMD. Hal ini terlihat pada kelompok kontrol, tidak ada responden memiliki sikap baik $(0 \%)$ dan setelah dilakukan penilaian kembali, ibu yang memiliki sikap baik menjadi $100 \%$. Sedangkan pada kelompok perlakuan sebelum diberikan edukasi sebanyak $7 \%$ responden memiliki pengetahuan baik dan setelah diberi penyuluhan, meningkat menjadi $26 \%$. Skor rerata sebelum diberikan penyuluhan sebesar 6,03 dan meningkat menjadi 8,27 setelah diberi penyuluhan.Hasil uji statistik diperoleh nilap $\mathrm{p}=0,000(\mathrm{p}<0,05)$ dapat disimpulkan bahwa ada perbedaan bermakna antara sebelum dan sesudah edukasi penyuluhan 
terhadap sikap responden tentang IMD pada kelompok perlakuan dan kontrol. Hal ini sesuai dengan penelitian sebelumnya (Ramlah S : 2014) dan Zakaria (2017) yang menyatakan bahwa pendidikan kesehatan dapat meningkatkan sikap ibu hamil dalam melakukan IMD.

Sebuah pendapat juga dibenarkan oleh Husnah (2014) yang mengatakan bahwa ada hubungan yang signifikan sikap ibu bersalin terhadap keberhasilan praktek menyusu dini. Penelitian ini selaras dengan penelitian yang dilakukan oleh Indramukti (2013) yang menyatakan bahwa ada hubungan antara sikap dengan praktik IMD pada ibu pasca bersalin normal. Sikap ibu mengenai pelaksanaan IMD dapat mempengaruhi pelaksanaan IMD. Sebab dapat mempengaruhi kesiapan ibu untuk melakukan IMD.

\section{KESIMPULAN DAN SARAN}

Berdasarkan hasil penelitian dapat disimpulkan bahwa ada perbedaan pengetahuan ibu hamil tentang IMD sebelum dan sesudahedukasi $(\mathrm{p}=0,000)$ baik pada kelompok perlakuan maupun kelompok control dengannilai $\mathrm{p}<0,05$ dan sikap ibu hamil tentang IMD sebelum dan sesudah edukasi $(p=0,000)$ berbeda antara sebelum dan setelah pemberian edukasi, baik pada kelompok perlakuan maupun kelompok control dengan nilai $\mathrm{p}<0,05$. Diketahui sebanyak 17 ibuhamildari 30 responden melaksanakan IMD setelah mendapatkan edukasi. Penelitian ini menyarankan agar adanya reward atau punishment terhadap para bidan yang membantu atau tidak membantu ibu bersalin melakukan IMD sehingga dapat meningkatka npelaksanaan IMD setiap persalinan

\section{DAFTAR PUSTAKA}

Bohari,dkk. (2011).PerubahanPengetahuan, Sikap Ibu Hamil Setelah Edukasi Dan Praktek Inisiasi Menyusu Dini Di Rsia Siti Fatimah Kota Makassar. Program Studi Ilmu Gizi Masyarakat Fakultas Kesehatan Masyarakat.
Husnah, (2014). Pengetahuan Dan SikapIbuBersalinDenganMenyusuiDi ni. JurnalKedokteranSyiah Kuala, Volume 14 Nomor 3 Desember 2014

Indramukti, (2013), Faktor Yang BerhubunganDenganPraktikInisiasiM enyusuDini (IMD) padaIbuPascaBersalin Normal Kemenkes RI. (2013). RISKESDAS. BadanPenelitiandanPengembanganKe sehatanKemenkes RI

Nurhikmah, dkk.

AnalisaPelaksanaanInisiasiMenyusuD ini (IMD) SebagaiUpayaPencegahan Primary Postpartum Haemorrhage Di RB SukoAsihSukoharjo. INFOKES, VOL.4 NO.2 September 2014

PERDA SUL-SEL. (2010). Air SusulbuEksklusif

Rahmawati, (2015). Hubungan Pengetahuan Dengan Sikap Ibu Tentang Inisiasi Menyusu Dini (IMD).Karya Tulis Ilmiah PRODI DIV Bidan Pendidikan Fakultas Kedokteran

Ramlah S, dkk. (2014).

EdukasiInisiasi Menyusu Dini

Terhadap Pengetahuan Sikap Ibu

Hamil di RSIA Pertiwi.Makasar.

Universitas Hasanuddin

Wahyuningsih,(2012).Hubungan

Pengetahuan Ibu Bersalin Dengan Inisiasi Menyusu Dini di Bidan Praktek Swasta Benis Jayanto Nge ntak Kujon Ceper Klaten.

Jurnal AKBID

Zakaria, (2017).Pengaruh Pendidikan Kesehatan Dengan Media Audio visual Terhadap Pengetahuan Dan Sikap Ibu Tentang Inisiasi Menyusu Dini Di Kota Yogyakarta. Tesis Prodi Magister Kebidanan. 